\title{
Depth of reading vocabulary in hearing and hearing-impaired children
}

\author{
Karien M. Coppens • Agnes Tellings • \\ Ludo Verhoeven $\cdot$ Robert Schreuder
}

Published online: 9 May 2010

(C) The Author(s) 2010. This article is published with open access at Springerlink.com

\begin{abstract}
The main point of our study was to examine the vocabulary knowledge of pupils in grades 3-6, and in particular the relative reading vocabulary disadvantage of hearing-impaired pupils. The achievements of 394 pupils with normal hearing and 106 pupils with a hearing impairment were examined on two vocabulary assessment tasks: a lexical decision task and a use decision task. The target words in both tasks represent the vocabulary children should have at the end of primary school. The results showed that most hearing pupils reached this norm, whereas most hearing-impaired pupils did not. In addition, results showed that hearing-impaired pupils not only knew fewer words, but that they also knew them less well. This lack of deeper knowledge remained even when matching hearing and hearing-impaired children on minimal word knowledge. Additionally, comparison of the two tasks demonstrated the efficacy of the lexical decision task as a measure of lexical semantic knowledge.
\end{abstract}

Keywords Vocabulary · Hearing impairment - Lexical decision · Use decision · Reading comprehension

In literate societies it is of great importance to be able to comprehend written discourse. Important information is contained in books, manuals, instructions, labels, and booklets, and in order to understand this information, vocabulary

K. M. Coppens $(\bowtie) \cdot$ A. Tellings $\cdot$ L. Verhoeven

Behavioural Science Institute, Radboud University Nijmegen, P.O. Box 9104, 6500 HE Nijmegen, The Netherlands

e-mail: K.Coppens@pwo.ru.nl

R. Schreuder

Donders Institute for Brain, Cognition and Behaviour, Centre for Cognition, Radboud University Nijmegen, P.O. Box 9104, 6500 HE Nijmegen, The Netherlands 
knowledge is of vital importance. It is well known that there is a relationship between vocabulary knowledge and reading comprehension (e.g., Aarnoutse \& Van Leeuwe, 2000; Anderson \& Freebody, 1981; Beck, Perfetti, \& McKeown, 1982; Curtis, Collins, Gitomer, \& Galser, 1983; Eldredge, 1990; Qian, 2002; Shiotsu \& Weir, 2007). Significant correlations between vocabulary knowledge and reading achievement scores have also been found in hearing-impaired students (LaSasso \& Davey, 1987; Paul \& Gustafson, 1991).

In general, hearing-impaired children show lower levels of reading comprehension than their hearing peers (e.g., Paul, 1998; Traxler, 2000; Wauters, Van Bon, \& Tellings, 2006a). More specifically, Wauters et al. (2006a) showed that hearingimpaired participants between 7 and 20 years performed at the reading comprehension level of 7-year-old hearing participants, on average. Only $4 \%$ of the hearing-impaired students in their study were reading at an age-appropriate level. The poor vocabulary (in terms of size and/or depth of semantic knowledge) of hearing-impaired students may limit their reading comprehension (Garrison, Long, \& Dowaliby, 1997; Kelly, 1996; Luetke-Stahlman \& Corcoran Nielsen, 2003; Paul, 2003; Wauters, Van Bon, Tellings, \& Van Leeuwe, 2006b). Studies have shown that both the vocabulary size of hearing-impaired children is smaller (Kelly, 1996; Pittman, Lewis, Hoover, \& Stelmachowicz, 2005), and their vocabulary knowledge is less deep (Kelly, 1996; Paul \& Gustafson, 1991; Traxler, 2000). Only a few studies examined the qualitative differences in deeper word knowledge more thoroughly in hearing-impaired students relative to hearing students. McEvoy, Marschark, and Nelson (1999) and Marschark, Convertino, McEvoy, and Masteller (2004) examined the structure and application of taxonomic knowledge in deaf students. Marschark et al. (2004) focused on superordinate-subordinate relations with a single-word association task, and the application of taxonomic knowledge was explored in McEvoy et al. (1999), using an analogies task. The responses of the deaf students in both studies were compared with responses given by hearing students. Their results showed that, in general, the conceptual knowledge of deaf students is less coherent and consistent than the conceptual knowledge of hearing students. However, they only used norms of hearing children and did not examine the way in which different levels of word knowledge relate to each other in both children with and without hearing impairments.

In the present study we investigated the achievements of hearing and hearingimpaired children on two vocabulary assessment tasks; a traditional lexical decision task and a 'use decision task'. A lexical decision task examines minimal word knowledge of a reader, namely, whether the reader recognizes a certain string of letters as a word of the target language. In order to recognize existing word patterns, the reader should have encountered the word before and stored it in his or her memory. A use decision task requires some knowledge of word meaning, namely, whether the reader recognizes (in)correct use of a word. Readers are presented with a target word and four short sentences in which the target word is used. They then have to choose in which sentence the target word is used best. For example, readers are presented with the target word train and the sentences: "The train sings", "The train sleeps", "The train goes", and "The train lies" and have to choose the sentence "The train goes" as the best answer. 
By contrasting the scores on these two tasks, we aimed to answer two different but related questions. First, are the size and depth of word knowledge the same for hearing and hearing-impaired pupils? We expected that hearing-impaired children were familiar with fewer words and that they knew them less well than hearing pupils. On balance, hearing-impaired children encounter fewer words than hearing children, because they are relatively deprived of linguistic input, at least with respect to spoken language. Second, is the relation between the two tasks similar for both groups? We expected that when hearing and hearing-impaired children scored similar on the lexical decision task, the hearing-impaired children would still score more poorly on the use decision task. Consequently, more often than hearingimpaired children, hearing children would make an item correct in the use decision task if they recognized the target word in the lexical decision task as an existing word. The reduced linguistic input hearing-impaired children receive, not only means coming across fewer words, but also coming across these words less often. In addition, encountering words frequently, in different contexts, helps to get a deeper knowledge of word meaning (Nagy, Anderson, \& Herman, 1987).

Additionally, by comparing the two tasks we investigated the efficacy of the lexical decision task as a measure of lexical semantic knowledge. Balota (1994) discussed variables on the whole word level that influence word recognition, such as word frequency. Previous studies suggested that lexical-level information is used in lexical decision tasks (Balota \& Chumbley, 1984). Marcolini, Burani, and Colombo (2009) also showed the use of lexical information in lexical decision tasks in research with children. These studies indicated that lexical decision is influenced by (some level of) word knowledge, and that during a lexical decision task also (some) deeper word knowledge is activated, although the task technically only requires pattern recognition. The performance on lexical decision was used successfully before as a predictor of scores on a vocabulary test (i.e., the Vocabulary Levels Test, Nation 1990) by Mochida and Harrington (2006). They found that the score on the lexical decision test was a strong predictor of performance on the Vocabulary Levels Test.

Presuming that the lexical decision task and the use decision task correlate strongly, the lexical decision task may be used as a measure of lexical semantic knowledge. The advantage of the lexical decision task is that it is easy to construct. The same task, containing target words that are different though similar in lexical characteristics, can be administered several times a year, making it possible to follow the development of children more closely.

Read (2000) raised the question about how to choose target words for vocabulary testing. The language sample used should reflect the goal of the test, for example, to examine a child's general level of vocabulary knowledge or a child's level on a certain norm. This study was designed to examine a pupil's vocabulary knowledge in terms of the expected reading vocabulary of children at the end of primary school, thus taking a domain referenced criterion. Perhaps not surprisingly, there are no surveys of the expected vocabulary of (hearing) Dutch children, except for a list of words 6-year old Dutch and Flemish children should preferably know orally (Schaerlaekens, Kohnstamm, \& Lejaegere, 1999). Therefore, we used words from the Cito Eindtoets Basisonderwijs [Cito End of Primary School Test, henceforward 
Cito test] of 2004, 2005, and 2006 to create a word list (www.cito.nl). Cito is an influential Dutch test institute that provides several school performance tests for primary and secondary schools. About $90 \%$ of the Dutch primary schools use the Cito test in the last grade of primary school, to determine which secondary school is suitable for their students. Furthermore, most secondary schools use the score on the Cito test as a criterion to place children at a certain school level. By using these tests to make a representative word list, we have a sample of words that can be viewed as an implicit norm for words known at the end of primary school. A detailed description of how the representative word list was created can be found in the "Methods" section.

In sum, in this study we examined the vocabulary knowledge of hearing and hearing-impaired children in grades 3-6 using a lexical decision task and a use decision task. By investigating the achievements on these two tasks we gauged the differences between levels of word knowledge for our two groups of readers, and we examined the utility of the lexical decision task as a measure of lexical semantic knowledge. The target words used represent an implicit norm for expected vocabulary knowledge at the end of primary school.

\section{Method}

\section{Participants}

The participants in this study were children in grades 3-6 from elementary schools throughout the Netherlands. In total, 518 children participated in this study. Four hundred and twelve children with normal hearing (216 boys and 196 girls) between the ages of seven and 14 years $(M=10$ years 3 months, SD $=1$ year, 1 month) participated and 106 students with hearing impairment (55 boys and 51 girls) between the ages of eight and 13 years $(M=10$ years 7 months, SD $=1$ year, 1 month).

Of the hearing children, 122 were in grade 3, 199 in grade 6, 58 in grade 7, and 33 in grade 8 . For the hearing-impaired children reporting the distribution is not as clear-cut since most children are in combined classes and move up according to both age and achievements. About 58 children were in grade $3 / 4$ and 48 in grade $5 / 6$. Thus, the hearing-impaired are not only significantly older $(t[159]=-3.37$, $p<.01)$ they also had more years of formal instruction.

Teachers supplied demographic data for the children pertaining to date of birth, gender, and IQ. If there were no official data on IQ, teachers were asked to rate the IQ of children on a 5-point scale, with three being average (100). The children in this study had no additional disabilities except for corrected vision, and they all had an IQ of at least 80. Children with a 1-rating were removed from the sample. All hearing-impaired children had at least an 80-decibel hearing impairment in the better unaided ear and 60 children had a cochlear implant. Of the 106 children with hearing-impairments, 25 were in mainstream settings and 81 were in special education schools. The hearing children in the sample are all classmates of the hearing-impaired children in mainstream settings. In the Netherlands, the tuition in 
special education for hearing-impaired children is bilingual by law. Furthermore, the language used at home for the children in mainstream settings was mainly a spoken language (14 used spoken Dutch and two another spoken language) or a combination of spoken Dutch and Sign (either Sign supported Dutch or Dutch Sign Language). Of the children in special education 13 used mainly a spoken language, 41 children used a combination of a spoken language and Sign (either Sign supported Dutch or Dutch Sign Language) and 22 children used mainly Sign supported Dutch, Dutch Sign Language, or a combination of both. Of five children the language used at home was not known.

\section{Materials}

\section{Target words}

As noted above, the study was designed to investigate vocabulary knowledge in terms of the expected vocabulary of children at the end of primary school. Therefore, we used words from the Cito test to create a representative word list.

We collected the texts of the Cito tests of 2004, 2005, and 2006 and created three databases (one for each year) containing the text in ASCII-format. These three databases were analyzed by Amazon/Casus (Coppen 1995), a computer system for automatic parsing of the Dutch language. With the Amazon program the three databases were syntactically analyzed and the output consisted of three lists with word tokens and their syntactic category. About 41,000 tokens have been analyzed $( \pm 5,300$ types) to create a word list with 3,533 lemmas (nouns, verbs, and adjectives). After this, a representative word list was created with 678 words that occurred in two or more years (in total 1,031 lemmas occurred in more than one test). For this study, 100 lemmas on the representative word list were randomly selected as target words.

\section{Lexical decision}

There are various formats of lexical decision tasks, such as the yes/no task (e.g., Beeckmans, Eyckmans, Janssens, Dufranne, \& Van de Velde, 2001; Mochida \& Harrington, 2006), the go/no-go task (e.g., Perea, Rosa, \& Gomez, 2002) and the paper-and-pencil lexical decision task (e.g., Gijsel, Van Bon, \& Bosman, 2004). In all these tasks children are presented with a string of letters that form either a word or a pseudoword, and they have to decide whether it is a word or not.

In this study we used a paper-and-pencil lexical decision task. For each of the target words a phonological and orthographical legal (Dutch) pseudoword was created. Participants knew that the test contained pseudowords, but they did not know how many. The pseudowords were created by comparing the target words with words in CELEX (Baayen, Piepenbrock, \& Van Rijn, 1993). We selected alternative words that were similar to the target words regarding CVC-structure and word class, and if possible regarding length and frequency of occurrence. This was done to ensure that variation in structure, word class, and length of the pseudowords approximately mirrored that of the target words. Target words could never be selected as an alternative for another target word. Thus selected, the alternative 
words were altered by one or two letters to create the accompanying pseudoword, while still maintaining phonetic and orthographic constraints of the Dutch language.

\section{Use decision}

The second task, the use decision task, was designed to measure whether the child recognized (in)correct uses of a target word. The task contained the same target words as the lexical decision task. Each target word was given together with four short sentences including the target word. At the beginning of each sentence stood the letter A, B, C, or D. Children had to choose in which sentence the target word was used best.

Research has shown that children with a large vocabulary benefit more from context (Curtis et al., 1983; Shore \& Kempe, 1999). Not only do they know more words in the sentence, if they come across an unknown word they also have more knowledge to derive its meaning. To control for the possibility that children with a large vocabulary might have a benefit in the use decision task, we constructed the sentences using simple words presumably known by all children participating. Therefore, we selected words that scored high on the Streeflijst Woordenschat [Target list vocabulary for 6-year-olds] (Schaerlaekens et al., 1999), meaning that most primary grade teachers expected 6-year olds to know these words. Consequently, both children with large vocabulary and children with poor vocabulary would benefit from the context equally. Only a limited amount of non-target words were used to construct the 400 sentences (i.e., four sentences for each word), since the same words could be used for different target words (for example sleep as a distracter for the target words train and patient in the sentences: "The train sleeps" and "The patient sleeps").

Given that it was our objective to assess whether children knew the target word and not whether they knew the surrounding words or understood the grammar, all sentences were written in the active voice, present tense, and kept as short as possible. The incorrect alternatives were syntactically and morphologically correct but semantically incorrect, for example: "the train sings", "the train sleeps", and "the train lies". The vivid imagination of children, stimulated by sentences such as "the train sleeps" in children's story books, was taken into account while constructing the alternatives. The risk that children take such sentences as the right alternative was minimized by asking children to choose the sentence in which the target word was used 'best'. Moreover, it might be expected that children in grade 3 and higher, also hearingimpaired children, know that "the train sleeps" happens in stories, but not in reality.

\section{Procedure}

In this study we investigated the word knowledge of children on 100 target words using two different tasks. Since this study is part of a larger experiment, the 100 target words of our study were presented at the same time as 80 other target words that were selected similarly (the same holds for the construction of the pseudowords).

The experiment was divided over three testing sessions to reduce the work-load. Each session consisted of a lexical decision task and a use decision task. To administer the lexical decision task, the 180 target words and 180 pseudowords were divided over 
three word lists; one for each session. Each list consisted of 60 target words and 60 pseudowords. Importantly, the 100 target words of our study were semi-randomly divided over the word lists, in order that the words were distributed equally over the three lists. After finishing the word list, the participants went along with a use decision task. This task contained the same target words as the preceding word list, though in a different order. The three sessions were spread over two or more daily periods. To control for order effects, there were four versions that were randomly divided over the classes. The tasks were administered in class by the first author.

As noted above, each session started with a lexical decision task. The instruction was given in the modality preferred by the children (Sign Language of the Netherlands or spoken Dutch). Children were asked to read the letter strings on the word list column by column and cross out the pseudowords. ${ }^{1}$ At the front of the first word list an example was given. Children had to cross out the pseudowords in the example themselves (as opposed to only the test leader), to make sure that they understood the intention of the task.

After finishing the lexical decision task, children received the instruction for the use decision task. In this task, the target word and four short sentences in which the target word was used were projected on a screen. After the item had disappeared, the screen turned black for a few seconds, and then the next item appeared. This procedure was applied to make sure that all children would finish the task in a reasonable time, and judged all items.

Children were instructed to read the target word and the four sentences, and to choose in which sentence the target word was used best. If they believed that there were two sentences in which the word was used correctly, they were instructed to choose the best answer. Participants were also instructed to guess an answer if they did not know the right answer. Children had to mark their answer on an answering sheet. To make sure that the child understood the intention of the task, the children made two examples at the beginning of the first use decision task and the instructor discussed the answers of these examples with the children.

During the second and third session a shortened version of the instructions was given, highlighting only the main points.

\section{Results}

\section{Correction for chance}

Before correcting for chance, scores were corrected for items that were omitted by children due to illness or such. The correction formula assumed that children would make the same amount of mistakes on the items they missed out on as on the items

\footnotetext{
${ }^{1}$ Children were not informed about the word-pseudoword ratio, because this would be like giving children a percentage of words they (should) know. To be able to discern existing words from pseudowords, children have to discriminate between letter strings they have encountered and stored, and letter strings they have never encountered and/or stored. So, actually, we ask children to cross out the words they do not know. Informing the children about the word-pseudoword ratio will force them to make guesses. Moreover, information about the ratio is usually not given in lexical decision tasks.
} 
Table 1 Hit rates and false alarm rates for the two groups

\begin{tabular}{|c|c|c|c|c|}
\hline & \multicolumn{2}{|c|}{ Unmatched groups } & \multicolumn{2}{|c|}{ Matched groups } \\
\hline & $\begin{array}{l}\text { Hearing } \\
(n=394)\end{array}$ & $\begin{array}{l}\text { Hearing-impaired } \\
(n=106)\end{array}$ & $\begin{array}{l}\text { Hearing } \\
(n=32)\end{array}$ & $\begin{array}{l}\text { Hearing-impaired } \\
(n=32)\end{array}$ \\
\hline Hit rate & $\begin{array}{l}M=.89 \\
\quad(\mathrm{SD}=.09)\end{array}$ & $\begin{array}{l}M=.72 \\
\quad(\mathrm{SD}=.21)\end{array}$ & $\begin{array}{l}M=.89 \\
\quad(\mathrm{SD}=.08)\end{array}$ & $\begin{array}{l}M=.89 \\
\quad(\mathrm{SD}=.08)\end{array}$ \\
\hline False alarm rates & $\begin{array}{l}M=.04 \\
\quad(\mathrm{SD}=.03)\end{array}$ & $\begin{array}{l}M=.19 \\
\quad(\mathrm{SD}=.20)\end{array}$ & $\begin{array}{l}M=.04 \\
\quad(\mathrm{SD}=.02)\end{array}$ & $\begin{array}{l}M=.04 \\
\quad(\mathrm{SD}=.02)\end{array}$ \\
\hline
\end{tabular}

they did make. Next, we used the correction index of Huibregtse, Admiraal, and Meara (2002) to correct the scores on the lexical decision task for guessing as well as for individual's response style. This index is based on the signal detection theory $(\mathrm{SDT}): I_{\mathrm{SDT}}=1-(4 h[1-f]-2[h-f]\{1+h-f\} /(4 h[1-f]-[h-\mathrm{f}]$ $\{1+h-f\}$ ), in which $h$ is the hit rate and $f$ is the false alarm rate. A hit is correctly recognizing a pseudoword as a non-existing word and crossing it out. A false alarm is incorrectly recognizing an existing word as a pseudoword and crossing it out. Huibregtse et al. (2002) defined a hit as correctly identifying a word as an existing word. They assumed that learners are presented visually with one word and are asked to indicate whether or not they know the meaning of the word and to answer with 'yes' or 'no'. However, in this study all items were presented at the same time on a paper and children were asked to cross out pseudowords, since this is more natural than crossing out an existing word.

To be able to compare the scores of the hearing and hearing-impaired children on the use decision task, we matched hearing and hearing-impaired children on their scores on the lexical decision task $(t<1)$. The matched sample consisted of a group of 32 children with normal hearing and a group of 32 children with a hearing impairment.

Hit rates and false alarm rates of both the unmatched and matched groups of hearing and hearing-impaired children can be found in Table 1. Index-scores were multiplied by one hundred to facilitate the comparison of these scores to the scores on the use decision task.

We used the correction for blind guessing (cfbg) to correct the scores on the use decision task. This formula is widely used in the field of language testing, for multiple choice items (Beeckmans et al., 2001). In the cfbg the participant has a chance of $1 / k$ to give the correct answer, $k$ being the total number of alternatives. For the use decision task $k$ was 4.

Data reduction

Children that had a score on one of the tasks that was at a greater distance from the median than 1.5 times the IRQ were removed from the sample. As a consequence 18 hearing children were removed from the data set and none of the hearing-impaired children. 
Analyses

The first research question of this study concerned the comparison of the group of children with normal hearing and the group of children with a hearing-impairment on the two vocabulary tasks to gauge differences in size and depth of reading vocabulary knowledge. The means and standard deviations of the corrected scores of the two groups of children on the two tasks can be found in Table 2. T-tests showed that hearing children did significantly better on the lexical decision task than hearing-impaired children: $t(111.22)=11.72, p<.01$ (two-tailed), and that they also performed significantly better on the use decision task: $t(106.42)=13.78$, $p<.01$ (two-tailed).

The second aim was to examine the relation between the two tasks for both groups. First, we examined whether the relation between the two tasks differed for hearing-impaired and hearing children. Therefore, the scores of the matched groups on the use decision task were analyzed. A two-sided $t$-test showed that the scores of the matched hearing and hearing-impaired children on the use decision task differed significantly, $t(42)=3.24, p<.01$. The means showed that the hearing children still scored higher on the use decision task than the hearing-impaired children even after matching the two groups on basic word knowledge.

Next, we examined whether hearing children, more often than hearing-impaired children, made an item correct in the use decision task if they recognized the target word in the lexical decision task. For each child we computed in what percentage of the cases that the child recognized a target word in the lexical decision task, he or she also recognized the correct use of that target word in the use decision task. For example, a child that recognized 93 target words in the lexical decision task and scored 64 of these 93 target words correct in the use decision task, received a percentage score of $67.4 \%$. Results showed that in $94.5 \%$ of the cases that a hearing child recognized an item in the lexical decision task, it also scored the item correct in the use decision task, whereas this percentage was only $66.4 \%$ for the hearing-impaired children. A $t$-test showed that this difference was significant, $t(107)=13.77, p<.01$ (two-tailed). Similar results were found if we examined this difference in the group of children that were matched on their scores on the lexical decision task: $t(42)=3.24, p<.01$ (two-tailed). In $95.0 \%$ of the cases that a hearing child recognized an item in the lexical decision task, it also scored the item correct in the use decision task, whereas this percentage was $89.8 \%$ for the hearing-impaired children.

Finally, the study was designed to investigate the efficacy of the lexical decision task as a measure of semantic knowledge. The results showed that achievements of the children on both tasks were strongly correlated with each other: $r=.89$, $p<.01$. The correlation in the group of hearing children was $r=.45, p<.01$ and in the group of hearing-impaired children even $r=.90, p<.01$.

If we picture the relation in a scatter plot, as in Fig. 1, two matters stand out. First, it can be observed that there is a large variation in scores within the hearingimpaired children. Some hearing-impaired children did as well as hearing children, whereas others achieved even below chance level. Second, it can be observed that almost all hearing children obtained a score of more than $85 \%$ on the use decision 


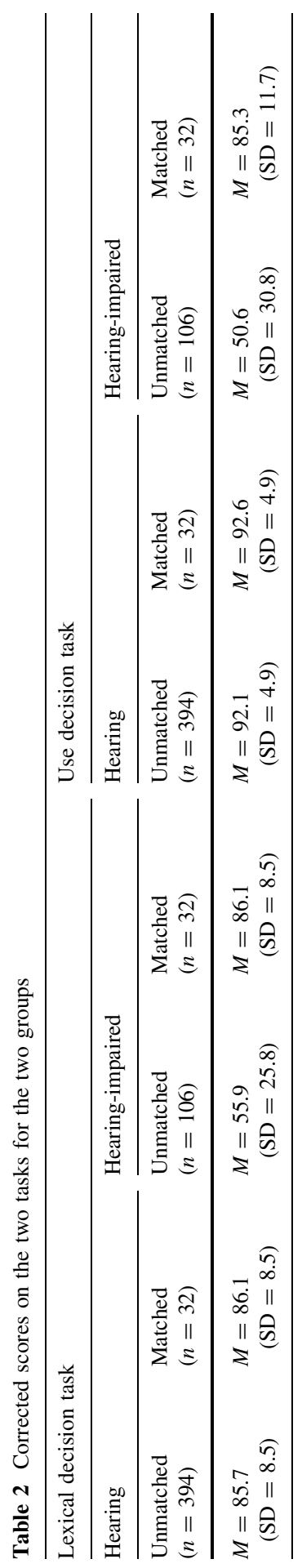



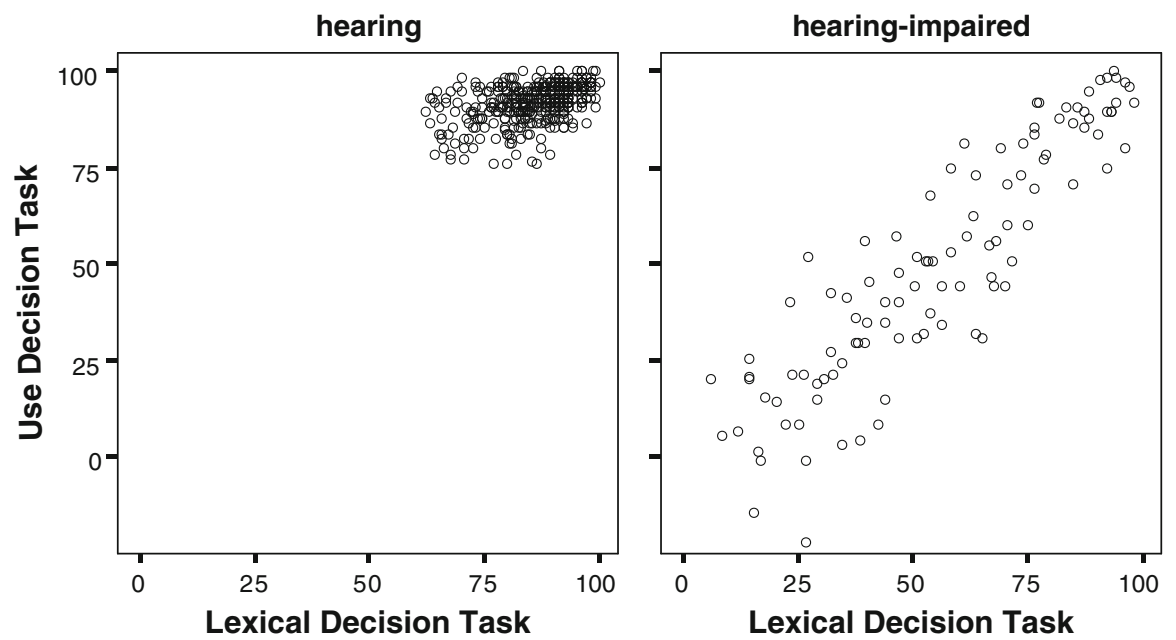

Fig. 1 Distribution of the corrected scores on both tasks for both groups

task. This supposed ceiling effect in the group of hearing children probably reduced the range in scores to such an extent that it was difficult to find a correlation. Nonetheless, a One-way ANOVA showed that the mean scores of the grades differed significantly for hearing children $(F[3,393]=13.96, p<.01)$. In grade 3 $(n=112)$ the mean score was $M=89.87$ ( $\mathrm{SD}=5.34)$, whereas this was higher in the other grades: grade $4(n=194, M=92.51, \mathrm{SD}=4.37)$, grade $5(n=57$, $M=83.41, \mathrm{SD}=4.58)$, and grade $6(n=31, M=94.72, \mathrm{SD}=3.87)$. Thus, the higher the grade, the better the score was.

\section{Discussion}

The purpose of our study was to examine the vocabulary knowledge of children with normal hearing and of children with a hearing impairment. Therefore, we administered a lexical decision task to assess minimal word knowledge and a use decision task to assess a deeper form of word knowledge. Our first aim was to ascertain whether hearing and hearing-impaired pupils knew the same amount of words and whether they knew these words to the same extent. In accordance with previous studies, our results showed that the hearing-impaired children both recognized fewer words than the hearing children in the lexical decision task, and recognized the (in)correct use of the target words less often in the use decision task.

Secondly, we wanted to investigate the relation between the two tasks in the two groups. Even if children recognize a pattern as an existing word in the lexical decision task, the question remains whether they also have lexical semantic knowledge of the word and can recognize its correct use. Our results showed that when hearing children and hearing-impaired children had a similar amount of minimal word knowledge, hearing-impaired children still scored more poorly on the use decision task. At the level of the individual words we found a similar difference. 
The chance that a child that recognized a word in the lexical decision task, would also recognize the correct use of this word in the use decision task, was greater for hearing children than for hearing-impaired children. This finding was robust when matching children with and without a hearing impairment on their scores on the lexical decision task. These results suggest that hearing-impaired children not only have smaller vocabularies, but that they also differ from hearing children with respect to the depth of their word knowledge.

These findings are similar to the results of McEvoy et al. (1999) and Marschark et al. (2004): there remained a qualitative difference in word knowledge between hearing-impaired and hearing children even when their minimal word knowledge was similar. A lack of linguistic input can account for these findings, reinforced by a Matthew effect (cf. Stanovich, 1986). Children with a hearing impairment do not only come across fewer words, they also come across these words less often. Moreover, hearing-impaired children probably also read less and are exposed to less written language than their hearing peers due to their inadequate vocabularies, and as a result they develop their vocabulary knowledge more slowly. Through frequent encounters with a word in differing contexts, children deepen their vocabulary knowledge, by learning the features and concepts related to the word, how to use it, and the multiple meanings of the word.

Although minimal word knowledge is a necessary condition for deeper word knowledge, it is not sufficient. Recognizing a word pattern and knowing the individual meaning of a word is a necessary start, but to comprehend discourse, the entire knowledge framework surrounding the word is essential (Paul, 1996). A practical implication of this is that vocabulary instruction should focus on integrating a word in a child's semantic network. Teachers may start with pronouncing and signing words and teaching the common meanings of words (and the focus should be on this for those children that score low on the lexical decision task, since they do not even recognize most word patterns). However, subsequently the instruction should move away from definition approaches, and focus on relating the word to knowledge a child already has, and encountering and using the word many times in many differing contexts (Paul \& Gustafson, 1991).

A final aim of our study was to investigate the efficacy of the lexical decision task as a measure of semantic knowledge; we did this by comparing the scores in the two tasks. The results showed that the scores on the two tasks were strongly related for both hearing and hearing-impaired children: children who scored at a high level on the lexical decision task also scored at a high level on the use decision task. Therefore, the lexical decision task can be used to obtain a general measure of vocabulary knowledge and to predict the score on a task that measures a deeper form of word knowledge. This is consistent with the finding of Mochida and Harrington (2006) that the performance of hearing students on the Yes/No test, another format of the lexical decision task, was a strong predictor of performance on the Vocabulary Levels Test (in this task children have to match target words to the correct definitions).

However, the variation in the hearing-impaired children was much larger than in the group of hearing children. This explains why the correlation between the two tasks was much stronger for children with a hearing impairment. The lexical decision task provided sufficient information to differentiate between hearing- 
impaired children, and it was a good predictor of deeper word knowledge in this group. Thus, lexical decision not only can be used as a first screening device in this group, but may even be sufficient as a measure of vocabulary.

The results showed that almost all hearing children scored more than $85 \%$ of the items correct on the use decision task, making it much more difficult to differentiate hearing children on minimal and deeper word knowledge with these two tasks. Nonetheless, the mean scores of the grades differ significantly and the higher the grade, the better the score. Our results showed that the children in grade 6 with normal hearing knew practically all target words. Knowledge of these target words is indispensable to comprehend the questions in the Cito test. Thus, hearing children most probably will not score at a low level on the Cito tests due to a lack of knowledge of the words used. However, many hearing-impaired children did not even have minimal knowledge of the target words, therefore, the Cito test cannot measure the general knowledge of hearing-impaired children; instead, it rather will reflect their (lack of) vocabulary knowledge.

There are great individual differences in the group of hearing-impaired pupils. It is important that future research tries to uncover what causes this large variation and which key features can predict whether and to what extent hearing-impaired children know the meaning of the words used in tests such as the Cito tests. As Prezbindowski and Lederberg (2003) indicated, an important issue might be the large variation in language input in hearing-impaired children and the fact that many children are exposed to more than one language, usually a sign language and a spoken language. A consequence of this might be that some low achieving children do have deep lexical semantic knowledge of a concept, but maybe only in sign language and not in written language. It should be examined how the variation in language input is related to differences in implicit metalinguistic knowledge and in syntactic knowledge. Perhaps low scores on the use decision task are explained by these differences: some sentences could be grammatically correct in Sign Language of the Netherlands, but not in written Dutch, and do therefore lead to typical 'deaf-mistakes'.

In sum, our results indicated that hearing-impaired children not only have problems due to the fact that they know fewer words, but also because they have less in-depth knowledge of words. In order to examine this difference in depth of knowledge, hearing and hearing-impaired children should be matched on minimal knowledge. Moreover, both the lexical decision task and the use decision task can be used to assess vocabulary knowledge of children with normal hearing and with hearing impairment. The lexical decision task even appears to be a good indicator for deeper vocabulary knowledge in hearing-impaired children.

Acknowledgments We thank Peter-Arno Coppen en Hans van Halteren of the Department of Linguistics for parsing the three databases containing the texts of the End of primary school tests of 2004, 2005, and 2006 with Amazon/Casus.

Open Access This article is distributed under the terms of the Creative Commons Attribution Noncommercial License which permits any noncommercial use, distribution, and reproduction in any medium, provided the original author(s) and source are credited. 


\section{References}

Aarnoutse, C., \& Van Leeuwe, J. (2000). Development of poor and better readers during the elementary school. Educational Research and Evaluation, 6(3), 251-278.

Anderson, R. C., \& Freebody, P. (1981). Vocabulary knowledge. In J. T. Guthrie (Ed.), Comprehension and teaching: Research reviews. Newark, DE: International Reading Association.

Baayen, R. H., Piepenbrock, R., \& Van Rijn, H. (1993). The CELEX Lexical Database. Technical report, Linguistic Data Consortium. Philadelphia, PA: University of Pennsylvania.

Balota, D. A. (1994). Visual word recognition: The journey from features to meaning. In M. A. Gernsbacher (Ed.), Handbook of psycholinguistics. New York: Academic Press.

Balota, D. A., \& Chumbley, J. I. (1984). Are lexical decisions a good measure of lexical access? The role of frequency in the neglected decision stage. Journal of Experimental Psychology, 10(3), 340-357.

Beck, I. L., Perfetti, C. A., \& McKeown, M. G. (1982). Effects of long-term vocabulary instruction on lexical access and reading comprehension. Journal of Educational Psychology, 74(4), 506-521.

Beeckmans, R., Eyckmans, J., Janssens, V., Dufranne, M., \& Van de Velde, H. (2001). Examining the Yes/No vocabulary test: Some methodological issues in theory and practice. Language Testing, 18(3), 235-274.

Coppen, P. A. (1995) A new version of the Amazon/Casus system. In P. De Haan, \& N. Oostdijk (Eds.), Proceedings of the Department of Language and Speech, Vol. 18 (1994), 85-90. Nijmegen: Radboud University Nijmegen.

Curtis, M. E., Collins, J. M., Gitomer, D. H., \& Galser, R. (1983). Word knowledge influences on comprehension. Paper presented at the meeting of the American Educational Research Association, Montreal, Canada.

Eldredge, J. L. (1990). Causal relationships between phonics, reading comprehension, and vocabulary achievement in the second grade. Journal of Educational Research, 83(4), 201-214.

Garrison, W., Long, G., \& Dowaliby, F. (1997). Working memory capacity and comprehension processes in deaf readers. Journal of Deaf Studies and Deaf Education, 2, 78-94.

Gijsel, M. A. R., Van Bon, W. H. J., \& Bosman, A. M. T. (2004). Assessing reading skills by means of paper-and-pencil lexical decision: Issues of reliability, repetition, and word-pseudoword ratio. Reading and Writing: An Interdisciplinary Journal, 17, 517-536.

Huibregtse, I., Admiraal, W., \& Meara, P. (2002). Scores on a yes-no vocabulary test: Correction for guessing and response style. Language Testing, 19(3), 227-245.

Kelly, L. (1996). The interaction of syntactic competence and vocabulary during reading by deaf students. Journal of Deaf Studies and Deaf Education, 1(1), 75-90.

LaSasso, C., \& Davey, B. (1987). The relationship between lexical knowledge and reading comprehension for prelingually, profoundly hearing-impaired students. The Volta Review, 89, 211-220.

Luetke-Stahlman, B., \& Corcoran Nielsen, D. (2003). The contribution of phonological awareness and receptive and expressive English to the reading ability of deaf students with varying degrees of exposure to accurate English. Journal of Deaf Studies and Deaf Education, 8(4), 464-484.

Marcolini, S., Burani, C., \& Colombo, L. (2009). Lexical effects on children's pseudoword reading in a transparent orthography. Reading and Writing, 22(5), 531-544.

Marschark, M., Convertino, C., McEvoy, C., \& Masteller, A. (2004). Organization and use of the mental lexicon by deaf and hearing individuals. American Annals of the Deaf, 149(1), 51-61.

McEvoy, C., Marschark, M., \& Nelson, D. L. (1999). Comparing the mental lexicons of deaf and hearing individuals. Journal of Educational Psychology, 91, 1-9.

Mochida, K., \& Harrington, M. (2006). The Yes/No test as a measure of receptive vocabulary knowledge. Language Testing, 23(1), 73-98.

Nagy, W. E., Anderson, R. C., \& Herman, P. A. (1987). Learning word meanings from context during normal reading. American Educational Research Journal, 24(2), 237-270.

Nation, I. S. P. (1990). Teaching and learning vocabulary. Rowley, MA: Newbury House.

Paul, P. V. (1996). Reading vocabulary knowledge and deafness. Journal of Deaf Studies and Deaf Education, 1(1), 3-15.

Paul, P. V. (1998). Literacy and deafness. The development of reading, writing, and literate thought. Upper Saddle River, NJ: Allyn and Bacon.

Paul, P. V. (2003). Processes and components of reading. In M. Marschark \& P. E. Spencer (Eds.), Oxford Handbook of deaf studies, language and education. New York: Oxford University Press. 
Paul, P. V., \& Gustafson, G. (1991). Comprehension of high-frequency multimeaning words by students with hearing impairment. Remedial and Special Education, 12(4), 52-62.

Perea, M., Rosa, E., \& Gomez, C. (2002). Is the go/no-go lexical decision task an alternative to the yes/no lexical decision task? Memory \& Cognition, 30(1), 34-45.

Pittman, A. L., Lewis, D. E., Hoover, B. M., \& Stelmachowicz, P. G. (2005). Rapid word-learning in normal-hearing and hearing-impaired children: Effects of age, receptive vocabulary, and highfrequency amplification. Ear and Hearing, 26(6), 619-629.

Prezbindowski, A. K., \& Lederberg, A. R. (2003). Vocabulary assessment of deaf and hard-of-hearing children from infancy through the preschool years. Journal of Deaf Studies and Deaf Education, $8(4), 383-400$.

Qian, D. D. (2002). Investigating the relationship between vocabulary knowledge and academic reading performance: An assessment perspective. Language Learning, 52(3), 513-536.

Read, J. (2000). Assessing vocabulary. Cambridge: Cambridge University Press.

Schaerlaekens, A. M., Kohnstamm, G. A., \& Lejaegere, M. (1999). Streeflijst woordenschat voor 6-jarigen [Target list vocabulary for six-year-olds]. Lisse: Swets \& Zeitlinger BV.

Shiotsu, T., \& Weir, C. J. (2007). The relative significance of syntactic knowledge and vocabulary breadth in the prediction of reading comprehension test performance. Language Testing, 24(1), 99-128.

Shore, W. J., \& Kempe, V. (1999). The role of sentence context in accessing partial knowledge of word meanings. Journal of Psycholinguistic Research, 28(2), 145-163.

Stanovich, K. E. (1986). Matthew effects in reading: Some consequences of individual differences in the acquisition of literacy. Reading Research Quarterly, 21(4), 360-407.

Traxler, C. (2000). The Stanford Achievement Test, 9th edition: National norming and performance standards for deaf and hard-of-hearing students. Journal of Deaf Studies and Deaf Education, 5(4), 337-348.

Wauters, L. N., Van Bon, W. H. J., \& Tellings, A. E. J. M. (2006a). Reading comprehension of Dutch deaf children. Reading and Writing, 19, 49-76.

Wauters, L. N., Van Bon, W. H. J., Tellings, A. E. J. M., \& Van Leeuwe, J. F. J. (2006b). In search of factors in deaf and hearing children's reading comprehension. American Annals of the Deaf, 151(3), $371-380$. 